\title{
Extraction of Tsunami Damaged Areas Due to the 2010 Chile Earthquake Using Optical and SAR Data of ALOS
}

\author{
Ni Made Pertiwi Jaya ${ }^{a *}$, Fusanori Miura a,b \\ a Graduate School of Science and Engineering, Disaster Prevention System Engineering, Yamaguchi University, Ube, \\ Yamaguchi 7558611, Japan \\ ${ }^{b}$ Regional Satellite Applications Center for Disaster Management (RSCD), Japan Aerospace Exploration Agency \\ (JAXA), 4-1-1 Industrial Technology Institute Asutopia, Ube, Yamaguchi 7550195, Japan \\ * Correspondence: madepertiwi@yahoo.com
}

Received: 6 April 2018; Accepted: 30 November 2018; Available online: 1 Desember 2018

\begin{abstract}
Information about damage areas is important due to the large-scale disasters worldwide. In the last decade, both optical and SAR remote sensing were applied in many disaster researches, such as tsunami damage detection. In this study, the ALOS AVNIR-2 and PALSAR images are used to extract the damaged areas caused by the 2010 Chile earthquake. In the processing of ALOS/AVNIR2 , the inundation area was estimated based on the NDVI calculation and classification. Furthermore, damaged areas of the ALOS/PALSAR are extracted by integrating the AVNIR-2 image for water mask and the DEM image for elevation mask. The damaged area result of AVNIR-2 is 8.91 $\mathrm{Km} 2$ and for the PALSAR is $8.72 \mathrm{Km} 2$ that is along the coastal areas. The image results showed a good agreement and corresponding area according to the institutional map of the inundation area. Future study in another area is needed in order to strengthen the processing method.
\end{abstract}

Keywords: tsunami damage areas; pptical and SAR data; ALOS

\section{Introduction}

A large-scale earthquake and tsunami affect thousands of people and cause serious damages worldwide in almost every year (Daniell et al., 2011). Information about damaged area immediately after a disaster is important in order to estimate the impact scale of the disaster (Joyce et al., 2009). However, disaster damaged areas are mostly a very difficult location to observe, so that investigation cannot be easily performed in the area. In the past, acquiring tsunami damage information was limited to only field surveys or using aerial photographs. In the last decade, remote sensing was applied in many tsunami researches, such as tsunami damage detection (Yamazaki and Matsuoka, 2007).

Recently space missions, such as Advanced Land Observing Satellite (ALOS) have concerned both Very High Resolution (VHR) optical images and Synthetic Aperture Radar (SAR) data (Rosenqvist et al., 2014). The on-board Advanced Visible and Near Infrared Radiometer type 2 (AVNIR-2) is the optical imagery of ALOS which has a high resolution imaging spectrometer operating in the visible and near-infrared (NIR) spectrum. The detection of tsunami damaged areas can be obtained from Normalized Difference Vegetation Index (NDVI) from the post-event imagery (Suppasri, 2012). Furthermore, the Phased Array type L-band Synthetic Aperture Radar (PALSAR) of ALOS is attempted to extract the tsunami disaster area by integrating the data with a Digital Elevation Model (DEM) data as an elevation mask and AVNIR-2 data as a water mask (Iseki, 2013).

In this study, the ALOS AVNIR-2 and PALSAR images are used to extract the damaged areas caused by the 2010 Chile earthquake tsunami disaster. A magnitude 8.8 earthquake struck off the central coast of Chile on 27 February 2010. Objectives of this research are to determine the ability of ALOS data both optical (ALOS/AVNIR-2) and SAR 
(ALOS/PALSAR) in extracting the tsunami damage areas and to compare both of the imageries analysis of damage areas caused by tsunami.

\section{Materials and Methods}

\subsection{Framework of Research}

The research frame work to obtain tsunami damaged areas can be seen in Figure 1.

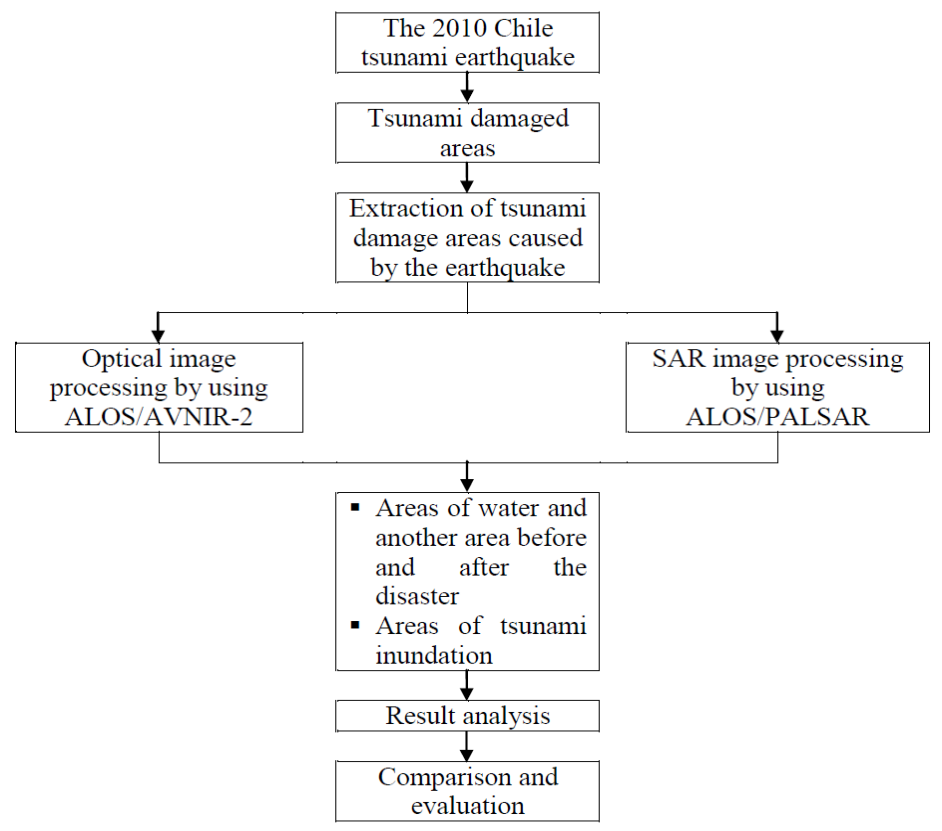

Figure 1. Framework of research

\subsection{Research Scheme}

In this study, the analysis is done by grasping the reflection characteristics of the ALOS images both AVNIR-2 and PALSAR before and after the disaster. The flowchart of the extraction method using AVNIR-2 images is shown in Figure 2 below.

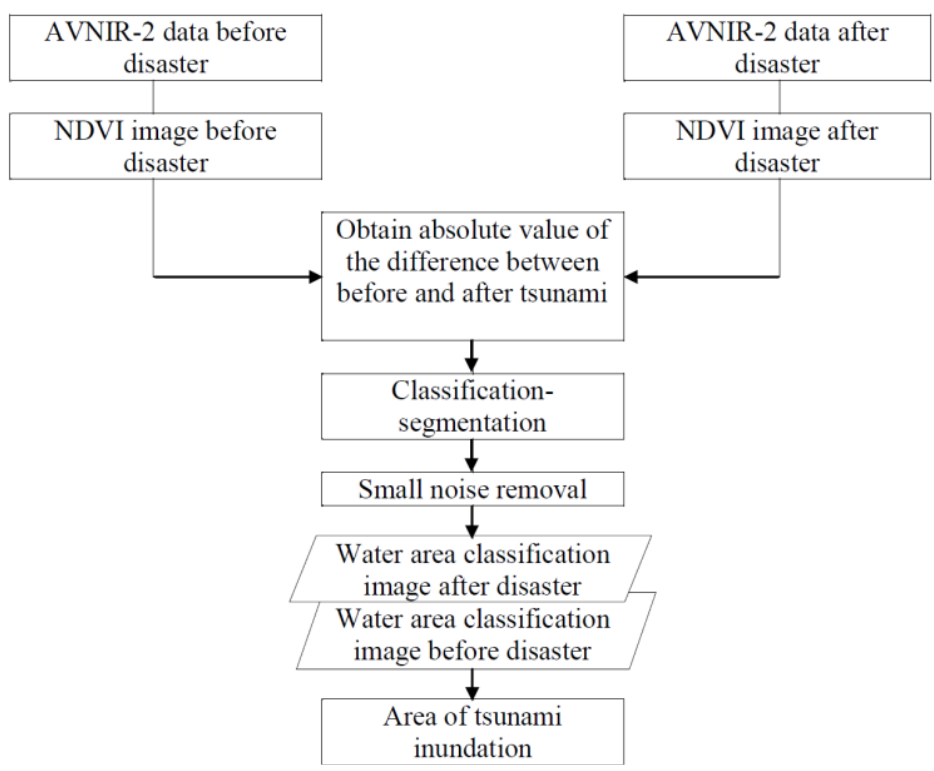

Figure 2. Fllowchart of the method of tsunami damage areas extraction sing ALOS/AVNIR-2 
A comparison was made and studied from ALOS/PALSAR data. Figure 3 showed the flowchart of the method of tsunami affected region extraction using ALOS/PALSAR.

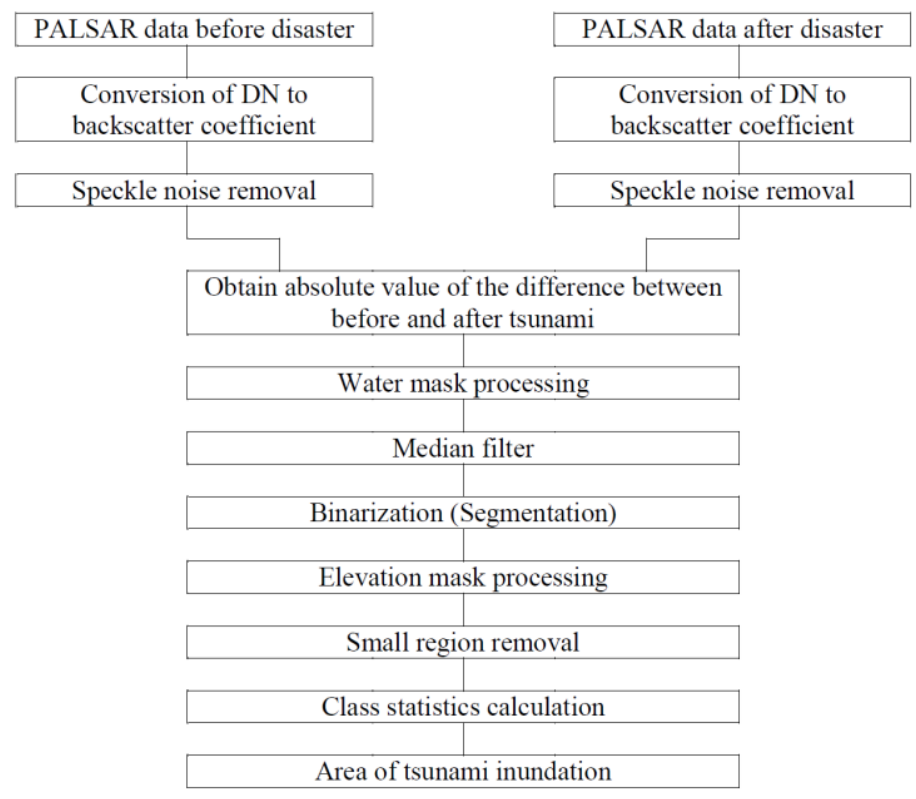

Figure 3. Flowchart ot the method of tsnami affected region extraction using ALOS/PALSAR

\subsection{Research Location}

The study area is located in Talcahuano and Concepcion which are strongly affected by the 2010 Chilean earthquake. Figure 4 below showed the research area using the true color imagery of the high resolution satellite image of QuickBird which is acquired after the disaster event on March $9^{\text {th }}, 2010$.

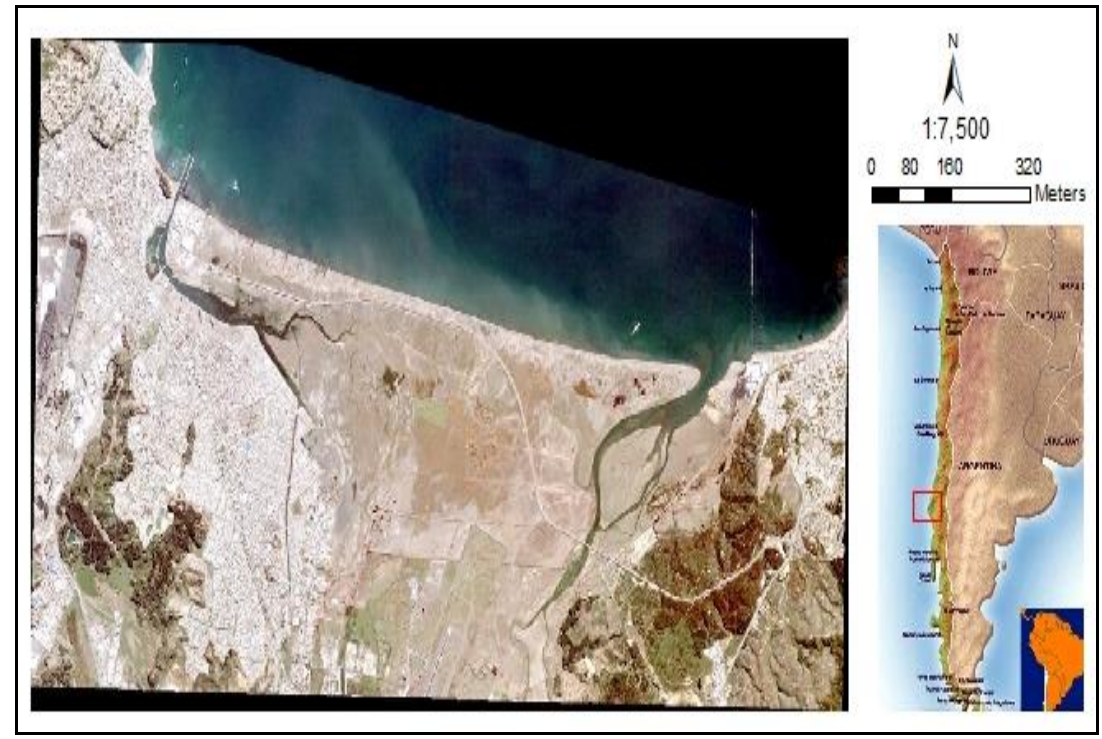

Figure 4. Research area (source: JSI, 2010)

\subsection{Data Source and Instrument}

Materials of this research are ALOS images provided by JAXA as shown in Table 1 . The other data are digital elevation model (DEM) data of ASTER GDEM with 30m resolution, QuickBird image with $5 \mathrm{~m}$ resolution from Japan Space Imaging and institutional map of inundation area in Talcahuano, Chile. Instrument used in this research are hardware 
computer, software ENVI 4.8, software ArcMap 10 on ArcGIS, and software Microsoft Office Excel.

Tabel 1. Lists of ALOS data used in the study

\begin{tabular}{cccc}
\hline Sensor & $\begin{array}{c}\text { Before } \\
\text { Tsunami }\end{array}$ & $\begin{array}{c}\text { After } \\
\text { Tsunami }\end{array}$ & Resolution \\
\hline PALSAR & $2009 / 3 / 11$ & $2010 / 3 / 14$ & $6.25 \mathrm{~m}$ \\
AVNIR-2 & $2007 / 2 / 24$ & $2010 / 9 / 4$ & $10 \mathrm{~m}$ \\
\hline
\end{tabular}

\subsection{Data Analysis}

The extraction of damaged areas from optical data of ALOS/AVNIR-2 is conducted by obtaining the NDVI index. It is obtained from the data before and after the 2010 Chilean earthquake in Chile. There are some processes for analyzing AVNIR-2 data, such as obtain absolute value of the difference between the image before and after tsunami, classification-segmentation, and small noise removal.

Image processing techniques for extracting tsunami damaged areas from ALOS/PALSAR consists of three stages that are pre-processing, analysis processing, and post-processing. The processes in pre-processing are speckle noises removal and conversion of the DN value into backscatter coefficient. Images after the pre-processing are used to obtain an absolute difference image and processed in analysis processing. Those processes are binarization process to divide water and another area, water mask processing to clearly show water areas, median filter process for reducing some disturbances, elevation mask processing based on the tsunami inundation height, and very small region removal. After removing some very small regions which are not necessary, the area calculation can be done to obtain the area of tsunami damaged areas.

\section{Results}

\subsection{Tsunami Inundation in Chili}

Coastal Chile has a history of very large earthquakes. Since 1973, there have been 13 events of magnitude 7.0 or greater. The February $27^{\text {th }}$ earthquake produced a tsunami that caused major damage locally over $500 \mathrm{~km}$ of coastline. The local tsunami water height and arrival times were influenced by bathymetry, coastal topography, aspect, fault slips, and localized subsidence and uplift due to the earthquake (Fritz et al., 2011).

An event recap report of the earthquake and tsunami event on February 27 $7^{\text {th }}, 2010$ has been written by Impact Forecasting LLC. It reported the area of tsunami inundation in some regions of Chile including the area of Talcahuano and Concepcion. Tsunami inundated areas are located along the coastal areas as can be seen on Figure 5.

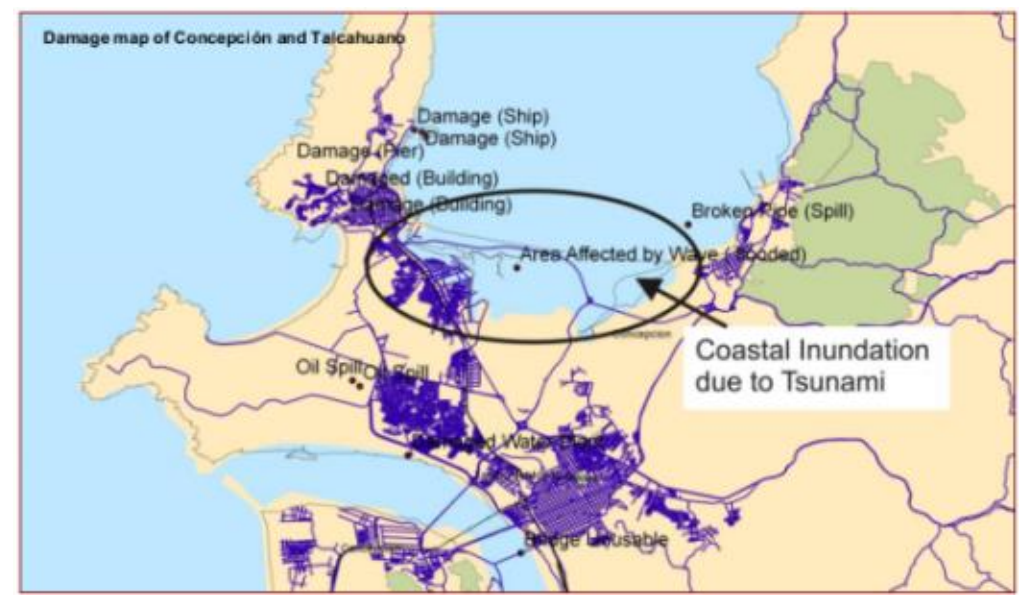

Figure 5. The damage map of conception and Talcahuano (source: AON benfield, 2010) 
There is also an inundation map provided by the government institution of Chile that is Secretaria Comunal de Panicacion, I. MunicipalidadI. According to the institutional map of inundation in Talcahuano area of Chile, the areas along the coast also showed as the vulnerable area of tsunami events. The inundation map is showed in Figure 6.

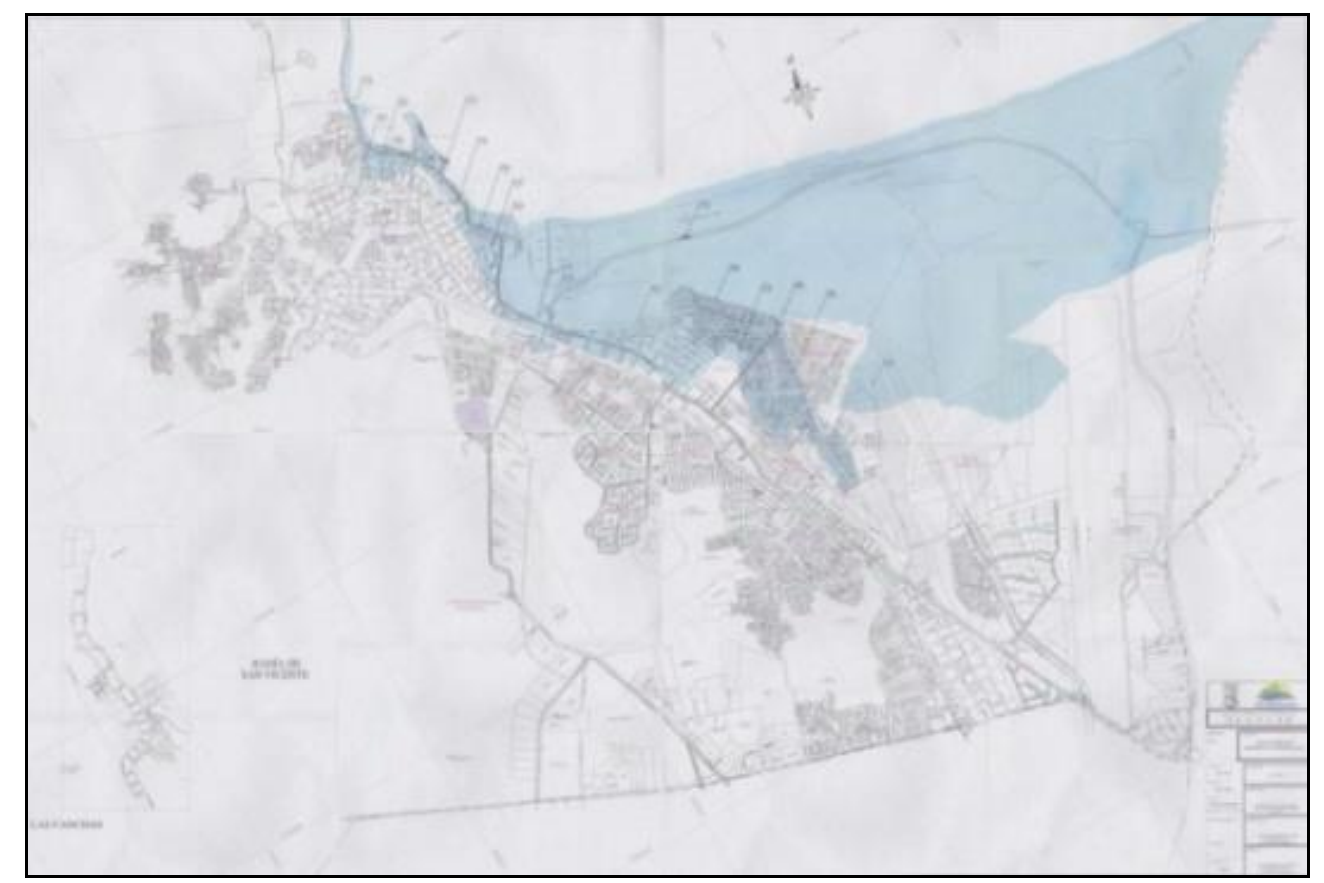

Figure 6. The inundation map in Talcahuano (source: Secretaria Comunal de Panicacion, 2010)

\subsection{Tsunami Damaged Areas Extraction Using ALOS/AVNIR-2}

Firstly, geometric correction is necessary to get a corresponding image for the next processes. After the correction process, images were resized according to the research area. Then, the tsunami inundation area was observed by obtaining the true color of the image. This method was used to represent the image close to its natural shades. Truecolor composite images are shown in Figure 7. In addition, the image also obtained from the false color synthesis as shown in Figure 8. This method can represent a red color on the image which means that the area have a strong activity of the plants.

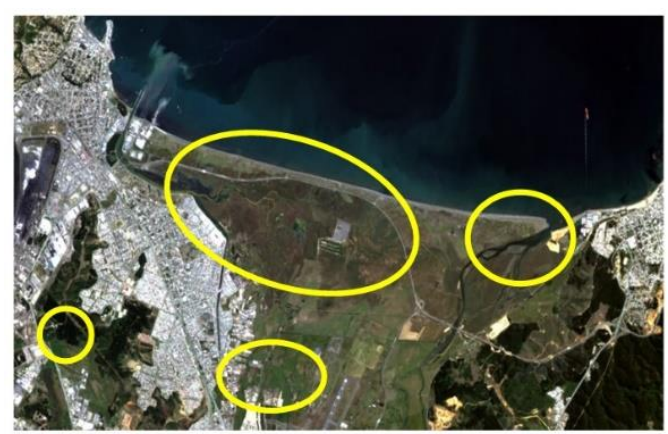

(a)

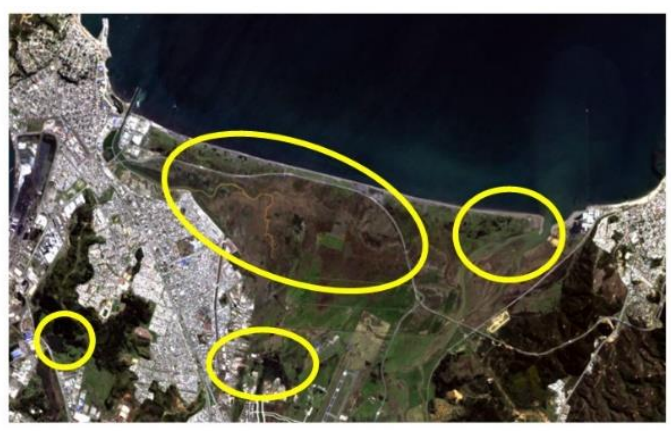

(b)

Figure 7. ALOS/AVNIR-2 true-color composite image: (a) image before the disaster $(2007 / 2 / 24)$ and $(b)$ image after the disaster $(2010 / 9 / 24) 1$ 


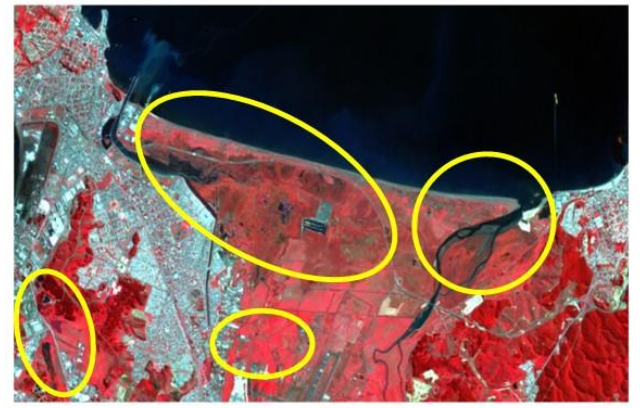

(a)

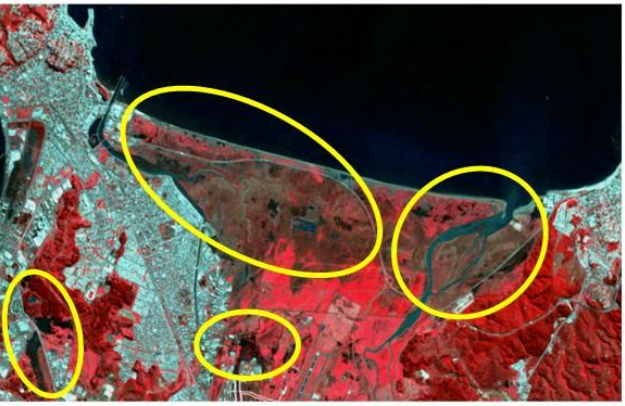

(b)

Figure 8. ALOS/AVNIR-2 false-color composite image: (a) image before the disaster $(2007 / 2 / 24)$ and (b) image after the disaster $(2010 / 9 / 24)$

The extraction of damaged areas was obtained by calculating the NDVI of images. The following is the equation for calculating the NDVI value of images:

$$
N D V I=\frac{N I R-R}{N I R+R}
$$

Where:

NIR: Near Infrared Band (Band 4 in ALOS AVNIR-2 image)

R: Red Band (Band 3 in ALOS AVNIR-2 image

The image which is calculated in grey scale can be obtained easily to understand the value of the NDVI. The value which shows the color close to the white color has a high activity of the plant, while a low activity in contrast has the value close to the -1 or shows the color of back. Figure 9 below showed the NDVI calculation and classification result of the image. Division processes were conducted using the NDVI image result, i.e. binarization, classification and small region removal. Some parts are obtained as inundation areas, such as areas along the coast, area near the airport and some parts around rivers. Classification images of the division processes as shown in Figure 10.

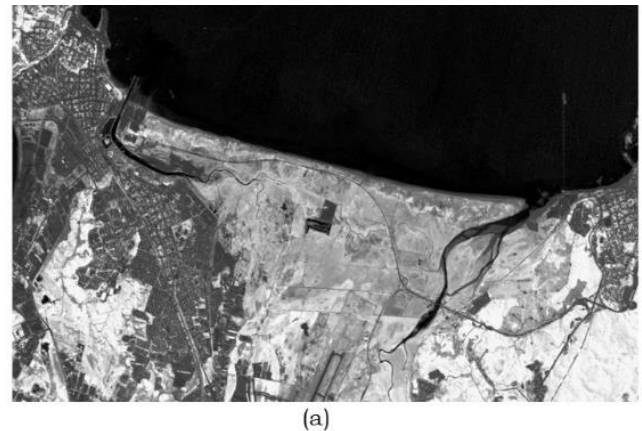

(a)

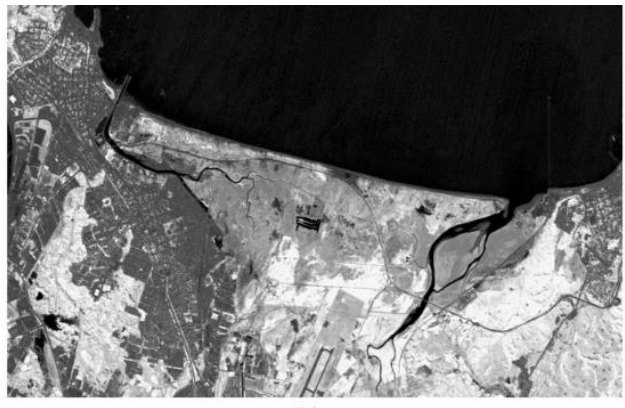

(b)

Figure 9. Computed NDVI image: (a) image before the disaster and (b) image after the disaster

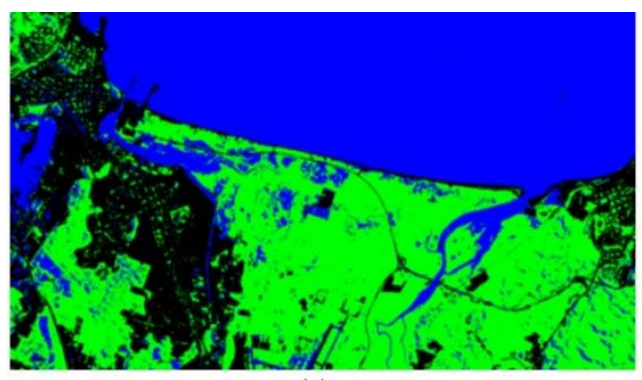

(a)

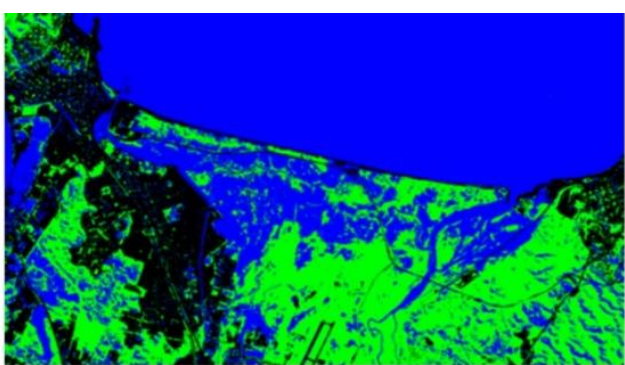

(b)

Figure 10. Classification image: (a) image before the disaster and (b) image after the disaster 
The area of inundation obtained from the image is $8.91 \mathrm{Km}^{2}$. In the case of the extraction using optical images of the ALOS/AVNIR-2, tsunami damaged areas are appeared as some patchy parts as shown in Figure 11. The area should be inundation areas since it is damaged by a tsunami. The distance of time between the disaster event and the satellite image is considered as the main reason of the image result. Some references informed that there were no post-disaster activities until eight months in the area of Talcahuano and Conception. So that, the condition has been remained the same for more than six months after the disaster was occurred. It made the extraction of damaged areas was possible to conduct using the AVNIR-2 image.

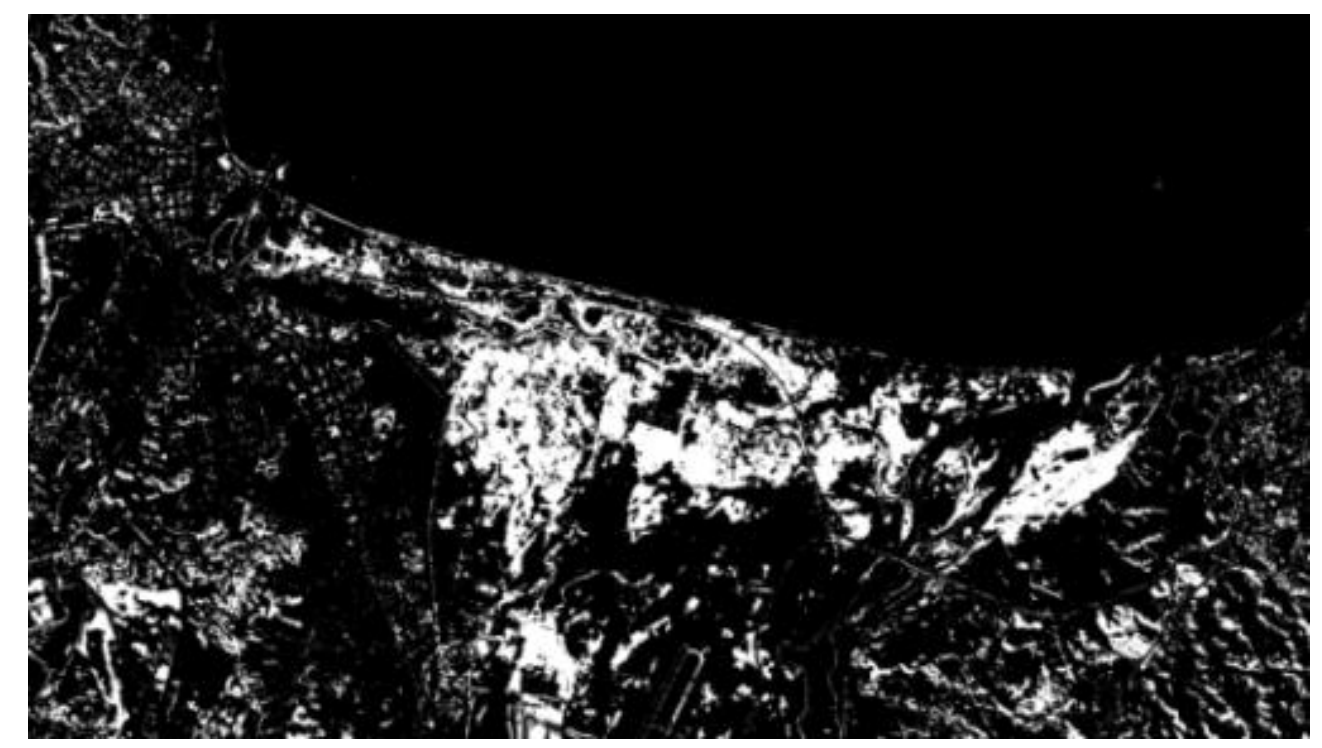

Figure 11. The ALOS/AVNIR-2 image result of tsunami damaged areas

\section{3 tsunami Damaged Areas Extraction Using ALOS/PALSAR}

In the pre-processing, first a geometric correction process was conducted. Then speckle noise removal was done by Lee filter processing to reduce the interference with the radar image and soften the image. The following is the equation for the processing:

$$
\left(\left|X_{a}-X_{b}\right|\right) R
$$

Xa: Estimate of the filtered image

$\mathrm{Xb}$ : The intensity of the image that does not exist speckle (un-speckle).

Calibration of PALSAR backscattering on the image through two stages, that are Beta Nought $\left(\beta^{\circ}\right)$ and Sigma Nought $\left(\sigma^{\circ}\right)$.

$$
\begin{gathered}
\beta^{o}=20 \times \log 10(D N) \\
\sigma^{o}=\beta^{o}+10 \log 10\left(D N^{2}\right)+C F
\end{gathered}
$$

Where (Dewantoro and Farda, 2012):

DN: Value of Converted Brightness

CF: Calibration Factor, that is -83

Figure 12 showed image results of speckle noise removal which performed in $21 \times 21$ pixels and Figure 13 showed images after calibration processes. 


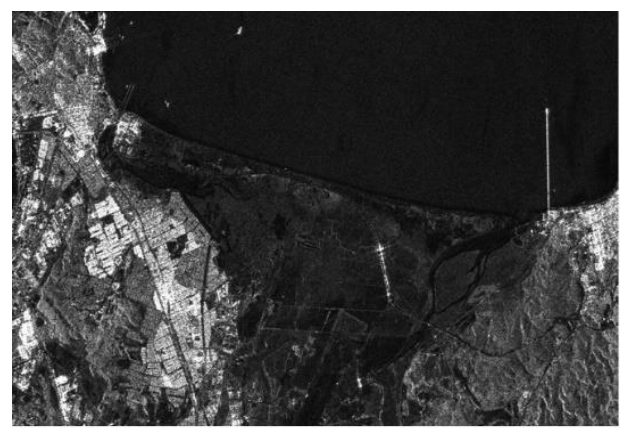

(a)

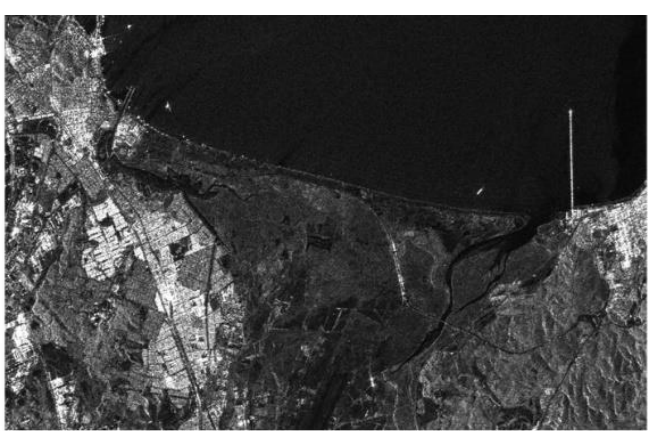

(b)

Figure 12. ALOS/PALSAR images after speckle noise removal: (a) image before the disaster and (b) image after the disaster

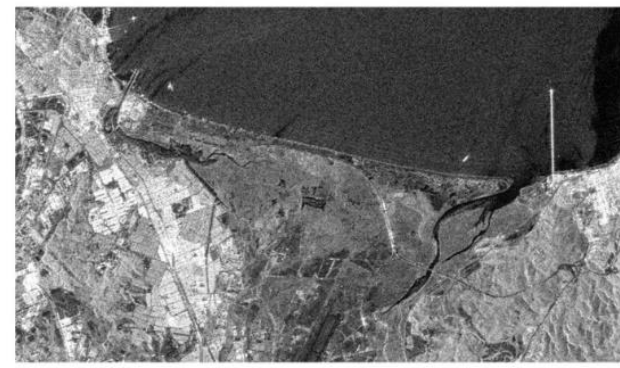

(a)

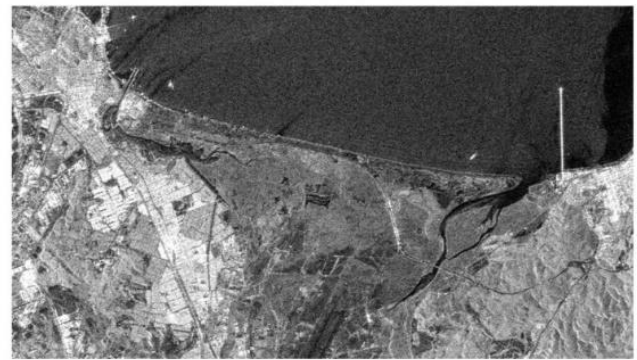

(b)

Figure 13. ALOS?PALSAR image after backscattering processing: (a) image before the disaster and (b) image after the disaster

In the case of obtaining tsunami damage areas, a mask for water and elevation is necessary. Water mask is created using band 4 (near-infrared) of the AVNIR-2 image before the disaster which clearly shows water area. The binarization and median filter processing are conducted after the water mask processing. After that, a DEM mask processing is generated from the ASTER GDEM image based on the range of tsunami inundation height. Those masks and image results are shown in Figure 14 below.

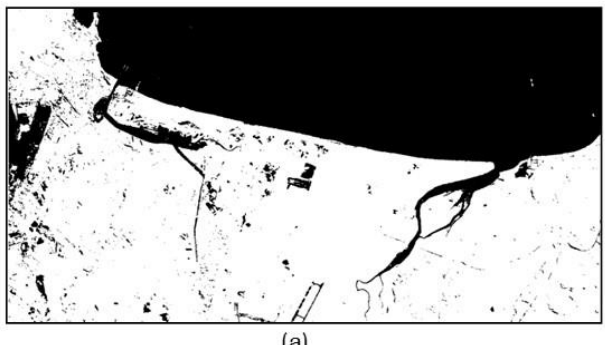

(a)

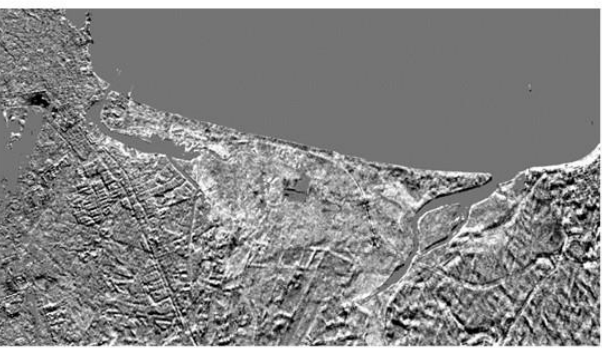

(b)

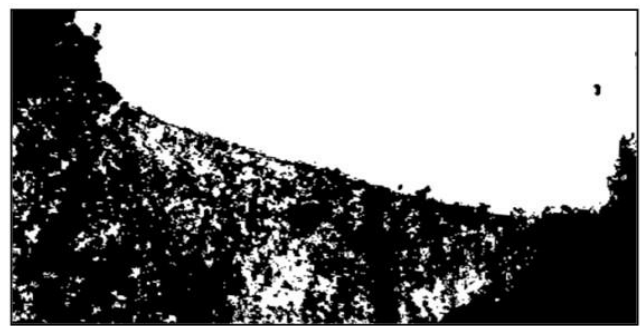

(c)

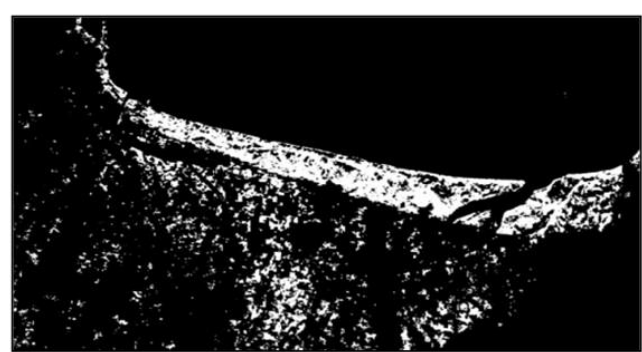

(d)

Figure 14. Water and DEM mask processing: (a) water mask (b) image result after applying water mask (c) elevation (DEM) mask and (d) iamge result after applying elevation (DEM) mask 
The last process of the analysis processing is the removal of very small regions which does not necessary in the image. The process of removing very small region is done by applying 1 time of closing-opening and 1 time of erode-dilate function on ENVI 4.8. From the statistics calculation, the area of inundation is $8.72 \mathrm{Km}^{2}$. There were some parts which showed inundation areas as shown in Figure 15, such as areas along the coast, area near the airport and some parts around river.

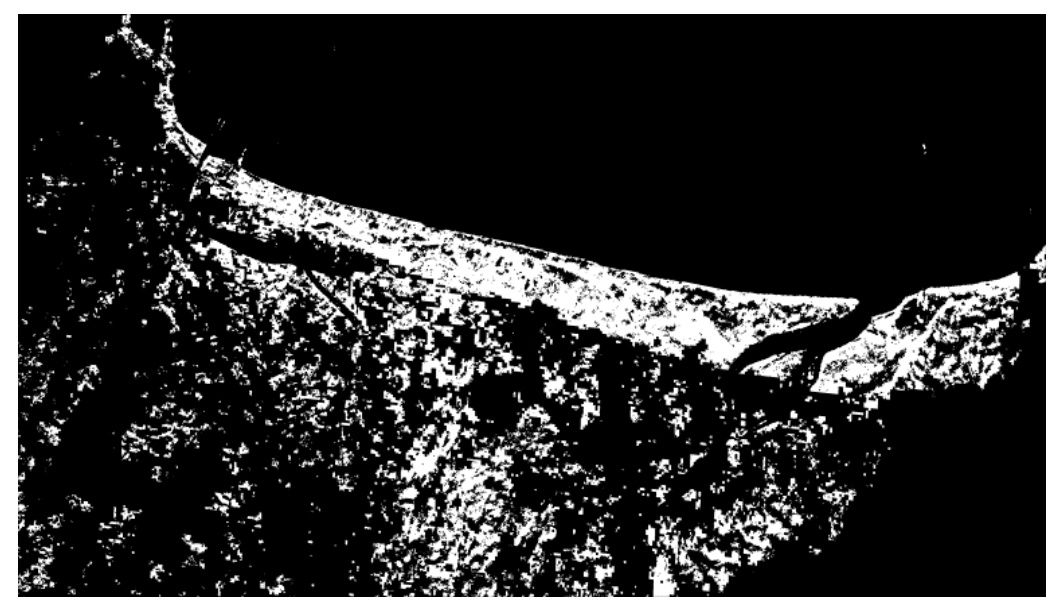

Figure 15. The ALOS/PALSAR image result of tsunami damaged areas

The PALSAR image result is also seen patchy due to the distance of times of the disaster and the image, as shown in Figure 14. However it still can be used to extract tsunami damaged areas. The image result showed that tsunami damaged areas is mostly located along the coastal area. Besides the observation date of the image, the DEM data that was used to mask the image is also affected the image result. A higher resolution of DEM image should be given clearer appearance of damaged areas on the image.

\subsection{Comparison of Image Extraction Result}

ALOS AVNIR-2 and PALSAR image results showed the same areas of inundation, such as areas along the coast, area near the airport and some parts around river. The area calculation result also showed a good agreement. The inundation area of the AVNIR-2 image is $8.91 \mathrm{Km}^{2}$ and the inundation area of the PALSAR image is $8.72 \mathrm{Km}^{2}$. Meanwhile, there are some differences of damaged areas distribution. There are some parts of damages areas in the AVNIR-2 image result which cannot be seen clearly in the PALSAR image result. Both of images are also shown damaged areas as patchy parts instead of inundated parts. By comparing those images to the institutional inundation map of Talcahuano, the image results showed a corresponding area due to the map. Damaged areas extracted from AVNIR-2 and PALSAR were overlay on the QuickBird image as shown in the Figure 16 below.

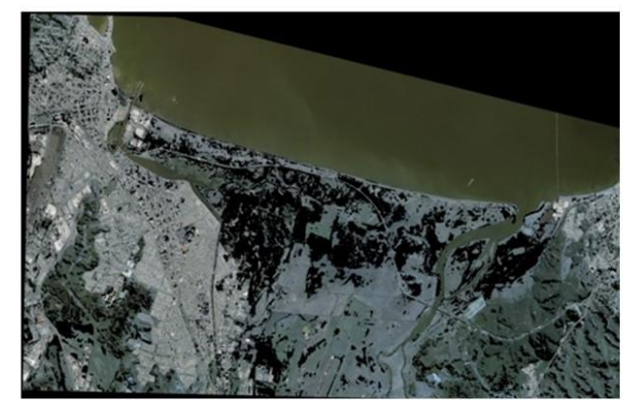

(a)

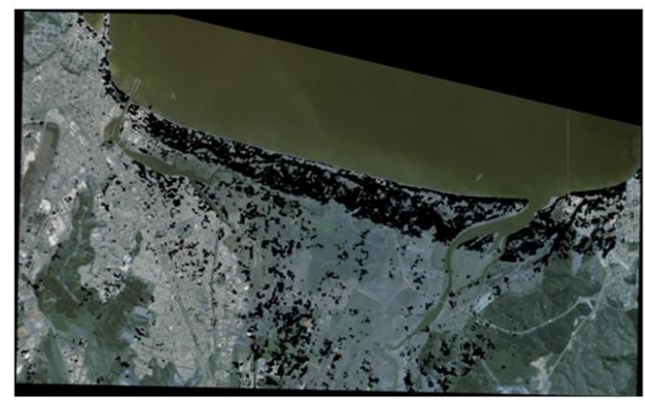

(b)

Figure 16. Extraction result of tsunami damaged areas using ALOS data: (a) the ALOS/AVNIR-2 image and (b) the ALOS/PALSAR image 


\section{Conclusion}

\subsection{Conclusions}

Based on the result of this research, satellite data of ALOS both optical (AVNIR-2) and SAR (PALSAR) showed a corresponding result in extracting tsunami damage areas due to the 2010 Chilean earthquake.

Extraction of the damage areas for the optical image of ALOS/AVNIR-2 is observed visually and applying a NDVI calculation to perform division processing. Tsunami damaged areas obtained from the image is $8.91 \mathrm{Km}^{2}$. While the process using SAR image of ALOS/PALSAR consist of pre-processing, analysis processing and post processing. One of the important processes was masking of water area and elevation. The area calculation result of the image is $8.72 \mathrm{Km}^{2}$. The extraction result gave a good agreement although there were some different in the distribution of the damage area. Those images also showed a corresponding result compare to the referenced inundation areas in Chile.

\subsection{Sugestion}

Future study is needed in order to make sure the processes of the extraction areas, such as examine the difference between satellite remote sensing result and in situ observation, try to analyze other events, make a preparation for the use of ALOS2/PALSAR-2 and other optical image with high space resolution, and use a higher resolution of DEM data to get better image result in the SAR processing.

\section{References}

AON Benfield. (2010). Event Recap Report: 02/27/10 Chile Earthquake. Chicago, USA: Impact Forecasting LLC.

Daniell, J. E., Khazai, B., Wenzel, F., \& Vervaeck, A. (2011). The CATDAT damaging earthquakes database. Natural Hazards and Earth System Sciences, 11(8), 2235-2251.

Dewantoro, M. D. R., \& Farda, N. M. (2012). ALOS PALSAR Image for landcover classification using pulse coupled neural network (PCNN). International Journal of Advanced Research in Computer and Communication Engineering, 1(5), 289-294.

Iseki, S. (2013). Extraction of Disaster Domain Caused by the 2011 Tohoku Earthquake Tsunami Disaster Using the ALOS/ PALSAR Images. Thesis. Yamaguchi, Japan: Yamaguchi University.

Joyce, K. E., Belliss, S. E., Samsonov, S. V., McNeill, S. J., \& Glassey, P. J. (2009). A review of the status of satellite remote sensing and image processing techniques for mapping natural hazards and disasters. Progress in Physical Geography, 33(2), 183-207.

JSI. (2010). QuickBird Image of Chile (March 9th, 2010). Japan: Japan Space Imaging.

Rosenqvist, A., Shimada, M., Suzuki, S., Ohgushi, F., Tadono, T., Watanabe, M., ... \& Aoki, E. (2014). Operational performance of the ALOS global systematic acquisition strategy and observation plans for ALOS-2 PALSAR-2. Remote Sensing of Environment, 155, 3-12.

Secretaria Comunal de Panicacion. (2010). Inundation Map of Talcahuano. Chile: I. Municipalidad.

Suppasri, A., Koshimura, S., Matsuoka, M., Gokon, H., \& Kamthonkiat, D. (2012). Application of remote sensing for tsunami disaster. Tokyo, Japan: InTech.

Yamazaki, F., \& Matsuoka, M. (2007). Remote sensing technologies in post-disaster damage assessment. Journal of Earthquake and Tsunami, 1(03), 193-210.

(C) 2018 by the authors; licensee Udayana University, Indonesia. This article is an open access article distributed under the terms and conditions of the Creative Commons Attribution (CC-BY) license (http://creativecommons.org/licenses/by/4.0/). 